\title{
Fundamental steps in experimental design for animal studies ${ }^{1}$
}

\author{
Passos fundamentais em desenhos experimentais de estudos envolvendo animais
}

\author{
José Eduardo de Aguilar-Nascimento² \\ 1. Article from Department of Surgery, Medical Sciences School, Federal University of Mato Grosso - Brazil. \\ 2. Professor of Surgery, $\mathrm{PhD}$
}

\begin{abstract}
Animal studies continue to have a vital role in science development. The aim of this review is to provide to new investigators an overview of the important steps involved in experimental designs and also to suggest some practical information that is commonly associated with this process. Investigators should adhere to the ethical procedure and follow strictly the scientific method. Both the aims and well-formulated hypothesis are essential and practical. In this regard a profound literature search and the aid of an experienced statistician is encouraged. The need of randomization, blinding, and attempting to minimize variation is discussed and recommended. The choosing of good control groups and the employment of pilot studies are useful. Finally, the formulation of new questions to be further responded is expected.
\end{abstract}

Key words: Research design. Animal experimentation. Models, animal. Epidemiologic methods

\section{RESUMO}

Estudos em animais continuam a ser vital para o desenvolvimento da ciência. O objetivo dessa revisão é o de apresentar a novos pesquisadores, uma visão geral dos passos importantes envolvidos no desenho experimental e, ao mesmo tempo, sugerir algumas informações de ordem prática que geralmente estão incluídas no processo da pesquisa. Os pesquisadores devem atentar sempre aos princípios éticos e seguir estritamente o método científico. Hipóteses bem formuladas e objetivas claros são essenciais e práticos. Nesse contexto, uma pesquisa bibliográfica profunda deve ser executada previamente e o pesquisador deve contar, se possível, com o auxilio de um estatístico experiente. A necessidade de randomização, de planejar um estudo cego e de se minimizar a variação são discutidas e enfatizadas. A escolha de bons grupos controles e o emprego de um estudo piloto são recomendados. Finalmente, a formulação de novas questões para serem respondidas por novas pesquisas é esperada.

Descritores: Desenho experimental. Experimentação animal. Modelos, animal. Método epidemiológico.

\section{Introduction}

Animal studies continue to have a vital role in science development. Experimental researches are the key studies for the development of new drugs and medical instruments as always have been in the past medical history. Moreover, the comprehension of a huge variety of physiological and patho-physiological conditions is only possible with animal experimentation. However, the current medical literature contains many animal studies showing bad shaped experimental designs. Unfortunately some authors ignore the principles of experimental designs generating uncorrected data and thus, reaching to wrong conclusions. Sometimes these experiments are unnecessary repetitive, unethical and as a result, waste both money and resources ${ }^{1,2}$.

The contribution of animal studies to clinical 
medicine requiresurgent formal evaluation. Systematic reviews and meta-analyses of the existing animal experiments would represent an important step forward in this process ${ }^{2}$. In this context, a recent metaanalysis involving 44 experimental studies on the use of different solutions for resuscitation after shock have shown that: 1) none of the studies had sufficient power analysis to correctly consubstantiate the conclusions on mortality, an important clinical endpoint, 2) only two studies explained how animals were allocated to the groups, 3) there was a huge heterogeneity between studies due to different bleeding induction, and 4) many biases were found ${ }^{3}$.

Animal experiments should inform decisions about what treatments should be taken forward in clinical trials only if their results are valid and precise. Biased or imprecise results from animal experiments may result in thetesting of biologically inert or even harmful substances inclinical trials, thus exposing patients to unnecessary risk and wasting scarce research funds ${ }^{3}$. Investigating the validity of animal experiments is therefore essential for both humanhealth and animals ${ }^{1,3}$. In the same way, reviewing the concepts of experimental designs is most important and motivating from time to time. Thus, the aim of this review is to provide to new investigators an overview of the important steps involved in experimental designs and also to suggest some practical information that is commonly associated with this process. The most experienced researchers may also review and debate the concepts recently included in the literature.

\section{General principles in research}

All research appears from the necessity in obtaining new information. Firstly, the design should define very well which information is aimed at. In other words, the investigator should state which is the question to be answered by the experiment. Once the question is stated, the method is delineated step by step, executed and then the data are collected. Data analysis is the next step and finally, the final text should provide new questions to be answered in further experiments. This cycle is vital for research lines.

There are two types of experiments. Confirmatory experiments aim at testing one or more hypothesis. For example, an experiment may be set up to investigate whether diet $\mathrm{A}$ is associated with greater immune response than diet B. Otherwise, exploratory experiments look at producing data that may be important for the generation of hypothesis to be tested. For example, an experiment could generate data that inform which is the normal value of some biochemical dosage in rats. However, in many times both confirmatory and exploratory experiments are overlapped in the same study ${ }^{4}$.

As a rule, all experiment should be presented in a way that allows other investigators to repeat it elsewhere. For that, all experiment should clearly inform the aim, the reason for choosing some animal model, the species, strain and source of the animals. Every details of the method should be stated including number of animals, method of randomization and information of the statistical method.

\section{Ethics in animal research}

The discussion on ethics in animal research is beyond the scope of this review. However, by the huge importance of the issue, a few words will be presented concisely.

During the last decade, it was seen an increasing interest among scientists on ethical principles ${ }^{5}$. Journals along the world are blocking papers that omit information whether they were approved or not by the local ethical committees. In our country, the Federal Resolution number 196 has created the CONEP (National Committee on Ethics in Research) in 1996. In many research centers along the country CEPs (Committee on Ethics in Research) were created supported by the resolution 196 . Although without a federal legal act on animal experimentation regulated, many Committees on Ethics in Animal Research emerged in different regions of Brazil. The Brazilian College on Animal Experimentation (COBEA) has published principles that are important to be known ${ }^{6}$. In 2003, during the 8th Congress of the Brazilian Society for the Development of Surgical Research (SOBRADPEC) in Belo Horizonte, a group of scientists have discussed and made important contributions to the federal animal act to be regulated.

The three Rs of Russel and Burch (1959) synthesized well the general principles that has to be followed in all animal research. All experiments should: 1) reduce the number of animals as possible, 2) replace animals for in vitro methods or use invertebrate animal models if available, and 3) refine the methods of investigation to minimize animal distress specially 
pain?.

Analgesia should be deliberately used in all surgical procedure for instances and humane endpoints are most recommended to be included in experimental designs. Although it is impossible to know what an animal feels, animals are sentient beings and any procedure that would reasonably be expected to cause more than momentary pain or distress in a human is expected to cause pain or distress in an animal $^{8}$. A deeper study on this issue before writing the design is most recommended for all investigators ${ }^{5-8}$.

\section{Literature search}

The project should begin with a solid bibliographic search. In the current days, the Internet is the most used weapon in searching, buying and/or free downloading articles. Some electronic addresses as the PUBMED (<http://www.ncbi.nlm.nih.gov/ $\underline{\text { PubMed/ }>)}$ ) and BIREME site (<http:// www.bireme.br/>) allow the access to different databases resulting in comfortable and powerful literature search. The Internet access is of major importance for investigators that reside far away from the universitary centers. The recent CAPES portal (< http://www.periodicos.capes.gov.br/>) has permitted to some Brazilian centers and universities free access to a huge number of international medical journals.

The most important points of a bibliographic search are: 1) increase knowledge on the investigated topic, 2) seek for articles related to the study, 3) find appropriate animal models, 4) identify methods already used, and 5) eliminate unnecessary duplication of experiments ${ }^{4}$. During literature search, investigators should pay attention to both new and pioneer studies on the field of the planned research. Relevant reports coming from the same country and especially from the same university or research center are imperative to be referred.

\section{Scientific method}

The most important point of the experimental design is its adherence to the scientific method. The scientific method could be synthesized in four phases: 1) observation and description of a scientific phenomena, 2) formulation of the hypothesis and the questions, 3) prediction of the results on the formulated hypothesis, and 4) implementation of the procedures to test the hypothesis by using appropriated methods ${ }^{1,4}$.

The objective of the study should be clearly stated. Moreover, the potential application of the findings arising from the experiment should be related to either human or animal conditions. The formulation of the hypothesis should predict two events: the null and the alternate hypothesis. The null hypothesis should assert that the treatment tested is not different from the control. In contrast, the alternate hypothesis should predict that the treatment tested actually differs from the controls ${ }^{4,9}$. Both the definition of the question to be answered by the experiment and the formulation of the hypothesis are vital at this stage of the project. The next phase of the experiment is the choice of the animal model followed by the pilot study.

\section{Animal models}

A good literature search should be performed to find out the adequate animal model. However, new investigators will find in good centers sufficient knowledge to follow practical advices from either tutors or senior staff. The key purpose of using animals in basic and applied research is to discover biologic phenomena and to model physiologic processes that are likely comparable to those that occur in humans. Thus, a good animal model should be reliable, practical and useful. An animal model must have some characteristics that resemble to the desired correlation (animal to humane extrapolation, for instances) ${ }^{9}$. For example, insulin was tested in rabbits because it was solidly established that insulin decreases blood glucose in rabbits as in humans though rabbits differs from humans in many ways. Ethically, the animals should be chosen by its lowest phylogenic scale ${ }^{7}$, adequacy to the planned procedures, and similarity to both humane anatomy and physiology. Of course, the costs should be considered ${ }^{8}$. Even the life span of an animal should be considered in long studies. In this context, the advise of an experienced veterinary is quite important at this point.

Animals models can be classified into: 1) spontaneous models, 2) experimental models, 3) genetically modified models, 4) orphan models, and 5) negative models ${ }^{4,9-11}$. Spontaneous animals models are those that exist in the nature with similarity to human condition or disease. Asthma in felines and the 
occurrence of natural killers cells (NK cells) in rats are good examples. Experimental models are those that need to be created to attend the desired conditions to be tested. Surgical models are examples of experimental or induced models. Molecular biology has permitted modifying the animal genoma to attain the aims of some studies. Genetically modified models are therefore created for that reason. Insertions of an alien DNA and the knock-out models are good examples of these animal models. Negative model or non-model is the term used for species, strains, or breeds in which a certain disease or condition does not develop. Negative models thus include animals that demonstrate a lack of reactivity to a particular stimulus. Their main application is in studies on the mechanism of resistance that seek to gain insight into its physiological basis. Why dogs do not develop arteriosclerosis is one of this questions that may be answered by a negative model. Contrarily, an orphan model is used to investigate either a condition or disease that occur in some species but not in humans. It may be important to recognize diseases that may affect humans in the next future. The mad-cow disease is the example of the day ${ }^{11}$.

\section{Variation control}

After choosing the animal model, the investigator should control variation. Uncontrolled variations may jeopardize the experiment in a way that all data may be invalidated ${ }^{12}$. The chosen model must be sensible to the treatment showing minimal variation of outcomes. Ancillary variables as gender, age and weight of the animal should be similar among the groups ${ }^{13}$. Preferentially, isogenic strains should be used. The laboratory environment may affect the course of an experiment. There is substantial evidence showing that many important biochemical data may vary with room temperature, and whether they were collect during day light or at night for instances ${ }^{12}$. Therefore, the experimental design must state the laboratory conditions and the data must be collected in the same period to reduce variation ${ }^{1,4,9,12}$. Special attention should be paid to the diet of animals. When testing different nutrients, the diets in all groups must be isocaloric and isonitrogenous. Personnel collecting data should be unchanged, qualified and trained in the procedures used in the project. If there are surgical procedures involved preferentially only one surgeon should perform all operations to avoid variation as well $]^{9,12}$.

Each experiment may contain a number of small experiments. When planning stratification of animals in groups, the assignment of animals at random to different groups and sub-groups may be improved by dividing animals in blocks to achieve minimal variation ${ }^{14}$. This technique is called "blocking" and allows less variation during randomization. For instances, if an experiment is aimed at investigating the anastomotic healing in two different time points in two groups, it will be then four treatment sub-groups. Thus, it will be better to allocate multiples of four similar animals per cage and then randomize them to receive the four treatments. Blocking in this way assures more balance between animals and minimizes variation in ancillary variables as weight and diet for example ${ }^{13,14}$.

\section{Important steps in experimental designs}

During the preparation of the study design, investigators should hold his attention in planning important steps before starting the study. These include the number of animals to be used, pilot studies, randomization, blinding, control groups, type of variables collected, and the statistical methods ${ }^{1,4,9}$. Although of prime concern in a research design, the statistical methods are beyond the scope of this paper and will not be considered here.

\section{Number of Animals}

The number of animals assigned to the experimental groups and sub-groups is vital. In this matter, a statistical staff may be important ${ }^{1}$. However, calculations can be easily done by on-line internet sites that investigators may consult. Examples of web sites are: <http//:www.biomath.info/ $>$; and $<$ http// www.stat.iowa.edu/ rlenth/Power//index.html $>$. Computer softwares may be also used to calculate the figures. Examples of special statistical packages most used are SPSS, SAS, and Epi-6.

Most of times, mathematical formulas are used. The identification of the number of animals to be used is fundamental to avoid the â error (1-power). 1power or the â error is the chance of obtaining a falsenegative result, i.e. the experiment will reject an untrue null hypothesis or a specified treatment effect ${ }^{15}$. Power analysis if possible must be calculated to ascertain 
the number of animals per group. Usually, $80 \%$ of power is addressed in the study, i.e., the investigator seeks for $80 \%$ chance to find a significant effect if it actually exists. In general, to calculate the number of animals required one must know: 1 ) the effect size (the estimated difference between the two groups), 2) the estimated standard deviation (for continuous variables), 3) the desired power (usually $80 \%$ ), and 4) the significance level (usually $5 \% ; p<0.05$ ) ${ }^{9,15}$. The first two factors are unique for the experiment and the other two are conventional. Dell et al. (2002) have presented an excellent review on this issue for further readings ${ }^{15}$.

\section{Pilot studies}

Before the beginning of the experiment, a pilot or a series of pilot studies should be carried out. This is an important step to assure that the entire experiment will work out fine. Frequently, a few number of animals is required though large number may be necessary. In experiments that an induced animal model is needed (intestinal anastomosis studies for example) the pilot study is the moment for the investigator to become skilled in the procedures involved. Moreover, pilot studies are also important to give an idea and calculate the size of the experiment, i.e. the number of animals that may be necessary ${ }^{4,9,15}$. Sometimes the original design is changed during the course of the pilot study due to the outcomes. Therefore, pilot studies should be minded by the investigator as a useful weapon for the strategy of the project ${ }^{9}$.

\section{Randomization}

Randomization is another valuable topic in the experimental design ${ }^{16}$. The allocation of animals to different groups of treatment should be at random: 1) to avoid biases, 2) to guarantee that groups have the same probability to receive a treatment, and 3) to control variation ${ }^{9,16}$. The method used to randomize should be clearly stated. Dices, envelopes containing pieces of papers with codes, and tables with random numbers are examples of some frequent methods used for randomization ${ }^{4}$. Experiments with either completely randomized groups or randomized blocking designs are all correct ${ }^{1}$. Blocking refers to direct manipulation to control one or more independent variables and thus, avoid variation ${ }^{4,14}$. Ancillary variables such as sex and weight may be firstly manipulated to confer minimal variation between the groups ${ }^{13}$. The investigator may divide the animals that are comparable in cages and then randomize them to the groups ${ }^{1,14}$.

Investigators should abort any temptation in rationalizing this step. In some occasions, investigators may be tempted to collect data in one group of treatment and after in other due to either technical or economical reasons. Imagine that is all set to collect data in only one of a two groups experimental study. It may appear to the investigator that it would be both rational and time saving to carry on and collect data in one of the groups firstly. However, this choice would jeopardize the whole experiment for the lack of randomization. Note that data should be collected in all groups at the same time, especially when operations are involved because skill in surgical procedure is progressive acquired. The second group may benefit of a more skilled surgeon!

\section{Blinding}

When two or more treatments are being compared, the investigator must diminish the occurrence of bias. Thus, the experiment should be done "blind" to diminish the possibility of a subjective effect in collecting data. Along the entire study, the main investigator may need collaborators. It is important to code animals, specimens, and samples, and also not to inform any coworker responsible for registering data about both the aims and groups of treatments investigated in the experiment ${ }^{4,9}$.

\section{Control groups}

Control groups should be planned with care. They are fundamental in experimental designs and should be preferred than historical comparison ${ }^{4}$. There are many types of control groups though the most important are the positive, negative, sham and comparative controls ${ }^{9}$. Positive controls are those in whom an effect or changes are most expected. They are necessary to estimate alterations that a condition may cause and then detect what the investigated treatment may modify. For example, the effect of two different diets on the recovery of malnutrition in rats must be compared with a positive control group studied during malnutrition. In a negative control no changes are expect. It is like a mirror of the positive 
control. In the above example, a negative control would be a group maintained with laboratory rat chow during all the experiment. Sham controls are used to mimic a procedure or treatment. For example, in a rat model of enterectomy, two treatments may be compared with a sham group submitted to the same laparotomy but instead of performing an enterectomy the bowel is only handled with care in the same site of resection of the resected group. Comparative control is a type of positive control in which it is used a known treatment to contrast with the new investigated treatment ${ }^{4,9}$.

\section{Types of variables}

An experimental study should use the same endpoints of a clinical study whenever is possible ${ }^{1-3}$. Surrogates of a clinical effect however are commonly used. During the construction of the study design investigators should attempt to the dependent variables. A variable can be continuous, ordinal, and categorical $^{4,16,17}$. Continuous variables are those expressed by numbers (serum glucose level, anastomotic bursting pressure, heart frequency, etc). When a score is used with a limited variation such as $0,+,++$, and +++ , the variable is termed ordinal. When it is considered an effect that may or may not occur such as death, infection or the occurrence of peritonitis for instances, the variable is said categorical. Whenever is possible the investigator should use continuous variables because an effect may be noticed earlier with few animals ${ }^{4,9,14}$. For example, instead of classify the results of serum glucose in diabetic (above $120 \mathrm{mg} / \mathrm{dL}$ ) and non-diabetic (below $120 \mathrm{mg} / \mathrm{dL}$ ) animals (categorical variable), the investigator should compare among the groups the means of the crude data.

\section{Final considerations}

It was emphasized the need of improvement in animal research. In this context, the planning of the experimental design is vital. Investigators should adhere to the ethical procedure and follow strictly the scientific method. Both specific question and wellformulated hypothesis are both essential and practical. In this regard a profound literature search and the aid of an experienced statistician is encouraged. The choosing of good control groups and the employment of pilot studies are useful. Finally, the formulation of new questions to be further responded is expected.

\section{References}

1. Festing MFW. Principles: the need for better experimental design. Trends Pharmacol Sci. 2003; 24:341-5.

2. Pound P, Ebrahim S, Sandercock P, Bracken MB, Roberts I; Reviewing Animal Trials Systematically (RATS) Group. Where is the evidence that animal research benefits humans? Br Med J. 2004;328:514-7.

3. Roberts I, Kwan I, Evans P, Haig S. Does animal experimentation inform human healthcare? Observations from a systematic review of international animal experiments on fluid resuscitaition. $\mathrm{Br}$ Med $\mathrm{J}$. 2002;324:474-6.

4. Johnson PD, Besselsen DG. Practical aspects of experimental designs in animal research. ILAR J. 2002;43:202-6

5. Goldenberg, S. Aspectos éticos da pesquisa com animais. Acta Cir. Bras. 2000;15:193-5.

6. Schnaider TB, Souza C. Aspectos éticos da experimentação animal. Rev Bras Anestesiol. 2003;53:27885.

7. Russell WMS, Burch RL. 1959. The Principles of Humane Experimental Technique. London: Methuen \& Co. Ltd. [Reissued: 1992, Universities Federation for Animal Welfare, Herts, England.] Avaliable from: (http:// altweb.jhsph.edu/).

8. Fitzpatrick A. Ethics and animal research. J Lab Clin Med. 2003;41:89-90.

9. Festing MFW, Altman DG. Guidelines for the design and statistical analysis for experiments using laboratory animals. ILAR J. 2002;43:244-58.

10. Fagundes, DJ; Taha, MO. Modelo animal de doença: critérios de escolha e espécies de animais de uso corrente. Acta Cir. Bras. 2004;19:59-65.

11. Davidson, M.K., Lindsey, J.R., and Davis, J.K. Requirements and selection of an animal model. Israel J Med Sci. 1987;23:551-5.

12. Howard BR. The control of variability. ILAR J. 2002;43:194-201.

13. Das REG. The role of ancillary in the design, analysis, and interpretation of animal experiments. ILAR J. 2002;43:214-22.

14. Shaw R, Festing MFW, Peers I, Furlong L. The use of factorial designs to optimize animal experiments and reduce animal use. ILAR J. 2002;43:223-32.

15. Dell RB, Holleran S, Ramakrishnan R. Sample size determination. ILAR J. 2002;43:207-13.

16. Altman DJ, Dore CJ. Randomization and base-line comparisons in clinical trails. Lancet. 1990;335:149-53.

17. Kinnear PR, Gray CD. SPSS for Windows. London: Psychology Press; 1994. 
Correspondence:

José Eduardo de Aguilar-Nascimento

Rua Estevão de Mendonça 81/801

78043-300 Cuiabá - MT

aguilar@cpd.ufmt.br
Conflict of interest: none Financial source: none

Received: October 15, 2004

Review: November 25, 2004

Accepted: January 06, 2005

How to cite this article:

Aguilar-Nascimento JE. Fundamental steps in experimental design for animal studies. Acta Cir Bras. [serial online] 2005 Jan-Feb;20(1). Available from URL: $\underline{\text { http://www.scielo.br/acb }}$ 